\title{
An Expanded Concept for the Glucose Effect in the Yeast Saccharomyces uvarum: Involvement of Short- and Long-term Regulation
}

\author{
By MAGDALENA PETRIK, OTHMAR KÄPPELI* AND ARMIN FIECHTER \\ Department of Biotechnology, Swiss Federal Institute of Technology, Hönggerberg, 8093 Zürich, \\ Switzerland
}

(Received 26 April 1982; revised 21 June 1982)

\begin{abstract}
When Saccharomyces uvarum was cultivated in continuous culture, it exhibited the typical growth behaviour of a glucose-sensitive yeast. Metabolic changes related to glucose-repressea growth were assessed by an analysis of overall culture parameters (biomass formation, ethanol and acetate production and gas exchange rates) and by measuring the mitochondrial cytochrome content. These functions were mainly affected by the glucose effect; the steady state values of these variables were first established in the chemostat as a function of dilution rate.

The short- and long-term regulation taking place when the cells were submitted to repression was assessed by administering glucose pulses and by shifts in the dilution rate. The primary response of the cells to the initiation of repressed growth was the formation of ethanol and acetate. Since there was no repression of oxygen uptake rate or cytochrome content prior to this response, it was concluded that ethanol and acetate formation was not the consequence of repression of respiratory activity, but resulted from the regulation of pyruvate dehydrogenase and pyruvate decarboxylase activities. Long-term adaptation of the cells occurred within 24 to $48 \mathrm{~h}$ of the initiation of repressed growth as manifested by a decrease of mitochondrial cytochrome content to the steady state value corresponding to that of repressed growth.
\end{abstract}

\section{INTRODUCTION}

Glucose metabolism in glucose-sensitive yeasts is known to have some remarkable features. Respiration, the formation of gluconeogenetic enzymes, as well as the synthesis of enzymes and transport systems involved in disaccharide utilization, are repressed in the presence of glucose (Linnane et al., 1972; Perlman \& Mahler, 1974; Witt et al., 1966; Polakis \& Bartley, 1965; Duntze et al., 1969; van Wijk et al., 1969; Zimmermann \& Eaton, 1974). Numerous biochemical studies concerning the so-called glucose effect in yeast have been published, but the mechanisms involved are still unknown. Genetic information is also limited. All the regulatory mutants obtained so far affect only certain segments of the whole complex of carbon catabolite repression (Montenecourt et al., 1973; Zimmermann \& Eaton, 1974; Schamhaart et al., 1975; Rytka et al., 1976; Ciriacy, 1978; Entian, 1980), or lead to a rather diffuse pattern of regulation (Ciriacy \& Breitenbach, 1979). In no case have the genetic elements and physiological effectors been identified which regulate repression and derepression of mitochondrial functions and enzymes.

The slow progress in the elucidation of mechanisms involved in glucose repression seems to be caused by a general absence of comprehensive cultivation techniques used in these studies. For instance, in order to establish in batch culture glucose-repressed and -derepressed states, substrate changes are required which generally involve centrifugation procedures. Furthermore, few data have been reported on the kinetics and the sequence of events observed that underly a classical repression/derepression description of the glucose effect. In our studies we took 
advantage of the continuous culture technique for establishing glucose-repressed and -derepressed cells.

By pulsing glucose into the culture and by applying dilution rate shift techniques in the chemostat, it was possible to demonstrate that a short-term (on/off) regulation of ethanol formation and a long-term adaptation of the mitochondrial cytochrome content occurs when the cells are submitted to repressed growth.

\section{METHODS}

Organism. Saccharomyces uvarum H2055 (from this Department), a glucose-sensitive yeast, was used in all experiments.

Medium. The synthetic medium had the following composition $\left[\mathrm{mg}(\mathrm{g} \text { glucose })^{-1}\right]:\left(\mathrm{NH}_{4}\right)_{2} \mathrm{SO}_{4}, 200$; $\left(\mathrm{NH}_{4}\right)_{2} \mathrm{HPO}_{4}, 64 ; \mathrm{KCl}, 30 ; \mathrm{MgSO}_{4} .7 \mathrm{H}_{2} \mathrm{O}, 15 ; \mathrm{CaCl}_{2} .4 \mathrm{H}_{2} \mathrm{O}, 10 ; \mathrm{FeCl}_{3} .6 \mathrm{H}_{2} \mathrm{O}, 0.5 ; \mathrm{ZnSO}_{4} .7 \mathrm{H}_{2} \mathrm{O}, 0.3 ;$ $\mathrm{MnSO}_{4} .2 \mathrm{H}_{2} \mathrm{O}, 0.6$; $\mathrm{CuSO}_{4} .5 \mathrm{H}_{2} \mathrm{O}, 0.08$; meso-inositol, 2; calcium pantothenate, 1; nicotinic acid, 0.2 ; pyridoxine. $\mathrm{HCl}, 0.5$; biotin, 0.001 . This medium was carbon-limited as judged by an $X-S_{0}$ diagram and was used throughout this work. Glucose was used at concentrations of 30 and $60 \mathrm{~g} \mathrm{l}^{-1}$. The medium was heat-sterilized $\left(121^{\circ} \mathrm{C}, 20 \mathrm{~min}\right)$ after reducing the $\mathrm{pH}$ to $2 \cdot 5-3.0$ with concentrated hydrochloric acid. For continuous cultivation, the sterilization was carried out in 3001 batches.

Culture conditions. The organisms were grown in a 101 bioreactor (Chemap AG, Männedorf, Switzerland) equipped with a flat blade turbine stirrer. The working volume was kept constant at 31 by a syphon. $\mathrm{A} \mathrm{pH}$ of 5.5 was automatically maintained with $10 \mathrm{~mol} \mathrm{NaOH} 1^{-1}$. The reactor was aerated with air at a flow rate of 300$4801 \mathrm{~h} \mathrm{~h}^{-1}$ corresponding to $1 \cdot 7-2.7 \mathrm{vol}$. air per vol. liquid $\mathrm{min}^{-1}$. The applied aeration rates yielded oxygen partial pressures above $30 \%$ of air saturation. The temperature was constant at $30^{\circ} \mathrm{C}$ and for agitation, a stirring speed of 900 r.p.m. was used. For a constant medium flow during continuous cultivation, Watson-Marlow MHRE 100 flow inducers (Falmouth, U.K.) were used.

Pulse and shift technique. The volume of the glucose solution pulsed into the fermenter (no other medium components were added) was between 3 and $5 \%$ of the total working volume. Addition of the pulse was carried out under sterile conditions to cells growing in steady state. Shifts in dilution rate were achieved by increasing the flow rate of the inflowing medium.

Sampling. In order to minimize the sample volume, samples were withdrawn with a syringe whose needle was inserted into the reactor, through a membrane, into the culture liquid.

Determination of biomass, glucose, ethanol and acetate. For measuring the biomass concentration, $10 \mathrm{ml}$ culture liquid was centrifuged at $2000 \mathrm{~g}$ for $5 \mathrm{~min}$ in previously tared centrifuge tubes. The sediment was washed twice with distilled water and then dried to constant weight at $105^{\circ} \mathrm{C}$.

Glucose was determined in a glucose analyser (YSI, Yellow Springs, Ohio, U.S.A.) with a detection limit of $100 \mathrm{mg} \mathrm{l}^{-1}$. Ethanol and acetate were analysed by gas chromatography (Hewlett Packard gas chromatograph 5830A, Avondale, Pa., U.S.A.). Prior to injection, the cells were removed by centrifugation and known amounts of methanol and propionic acid were added as internal standards. The columns were as follows: for ethanol, Propack QS, mesh $100-120$, stainless steel, $6 \mathrm{ft}(1.8 \mathrm{~m})$; for acetate, $10 \% \mathrm{SP}-1200,1 \% \mathrm{H}_{3} \mathrm{PO}_{4}$ on $80 / 100$ Chromosorb WAW, glass column, $6 \mathrm{ft}$. For both columns the temperature was $150^{\circ} \mathrm{C}$.

Gas exchange rates. The specific oxygen uptake rate $\left(Q_{\mathrm{O}}\right)$ and carbon dioxide production rate $\left(Q_{\mathrm{Co}}\right)$ were calculated from the data provided by a gas analyser (Hartmann \& Braun, F.R.G.) connected to the air outlet of the reactor, and were based on an inert gas balance.

Determination of cytochrome content. Cytochromes were determined according to Gmünder et al. (1981).

\section{RESULTS AND DISCUSSION}

\section{Growth and respiratory activity of $S$. uvarum in continuous culture}

The yeast $S$. uvarum showed the typical growth pattern of a glucose-sensitive yeast (Fiechter $e t$ al., 1981). Up to a dilution rate of $0 \cdot 16 \mathrm{~h}^{-1}$ the breakdown of glucose was purely oxidative (Fig. 1). Biomass and $\mathrm{CO}_{2}$ were the only products formed.

The R.Q. was slightly below unity, indicating a stoichiometric oxidation of glucose. The oxygen uptake rate and carbon dioxide production rate of the culture increased linearly with specific growth rate to a maximum value of approximately $5.5 \mathrm{mmol} \mathrm{g}^{-1} \mathrm{~h}^{-1}$ at a dilution rate of $0 \cdot 16 \mathrm{~h}^{-1}$. The yield of biomass on glucose was 0.47 at low dilution rates and increased to 0.53 at $0 \cdot 16 \mathrm{~h}^{-1}$. The glucose uptake rate at a dilution rate of $0 \cdot 16 \mathrm{~h}^{-1}$ was $2 \mathrm{mmol} \mathrm{g}^{-1} \mathrm{~h}^{-1}$.

The region of growth rates above $0 \cdot 16 \mathrm{~h}^{-1}$ was characterized by a decrease in biomass yield (yield $=$ approximately $0 \cdot 1$ ) and the accumulation of glucose and ethanol in the medium. The 

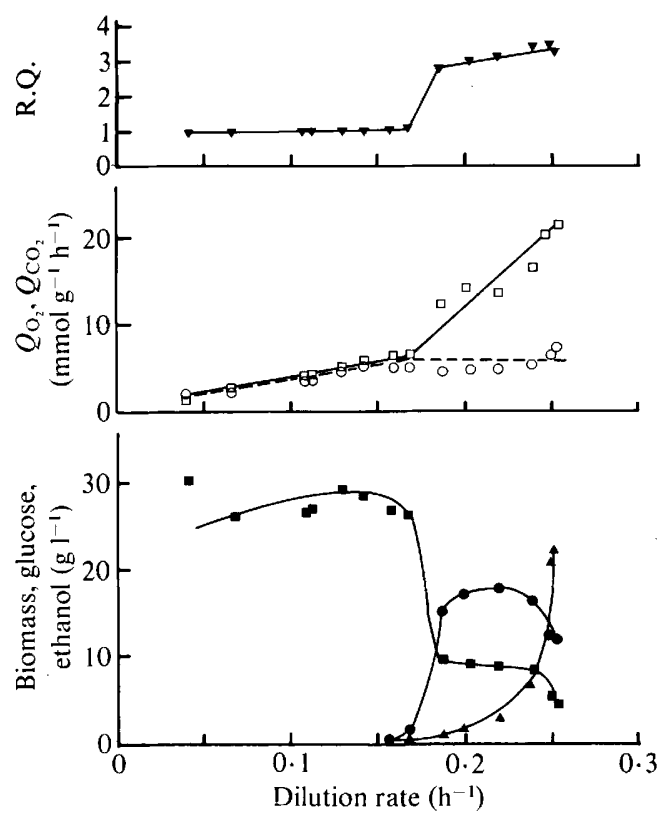

Fig. 1. Influence of the dilution rate on steady state biomass $(\square)$, glucose $(\boldsymbol{\Lambda})$ and ethanol $(\boldsymbol{O})$ concentration, the specific oxygen uptake rate $\left(Q_{\mathrm{O}_{2}}\right)(\mathrm{O})$ and carbon dioxide production rate $\left(Q_{\mathrm{CO}_{2}}\right)(\square)$ as well as the respiratory quotient (R.Q.) $(\nabla)$ in a chemostat culture of $S$. uvarum with a reservoir glucose concentration $S_{0}=55 \mathrm{~g} \mathrm{I}^{-1}$.

increased $\mathrm{CO}_{2}$ production rate led to a R.Q. value above 2, indicating that glucose was only partly oxidized. The oxygen uptake rate remained at the level reached at the dilution rate of $0.16 \mathrm{~h}^{-1}$. This is in accordance with the observations made by Barford \& Hall (1979) who found no repression of respiration in Saccharomyces cerevisiae grown under glucose excess conditions. Previous data on $S$. cerevisiae as summarized by Fiechter et al. (1981) are currently being reexamined. Differences in the metabolic behaviour of the cells seem to be possible and are mainly due to the composition of the medium used by the different authors $(\mathrm{O}$. Käppeli, unpublished observations). Steady states were established up to a dilution rate of $0.25 \mathrm{~h}^{-1}$, indicating a critical dilution rate of approximately $0.26 \mathrm{~h}^{-1}$ for $S$. uvarum.

\section{Steady state cytochrome content}

Cytochrome $c$ increased sharply with increasing dilution rate under glucose-depressed growth conditions (Fig. 2). Its steady state content was approximately doubled when the dilution rate changed from 0.04 to $0.15 \mathrm{~h}^{-1}$. Cytochrome $b$ also increased with increasing dilution rate up to values where glucose repression became effective. Cytochrome $a$ showed no uniform correlation with the dilution rate. From the data of the oxygen uptake rate and the cytochrome content, no direct relationship can be established between the two parameters. The oxygen uptake rate increased linearly from $1.5 \mathrm{mmol} \mathrm{g}^{-1} \mathrm{~h}^{-1}$ at $D=0.04 \mathrm{~h}^{-1}$ to $5.5 \mathrm{mmol} \mathrm{g}^{-1} \mathrm{~h}^{-1}$ at $D=0.16 \mathrm{~h}^{-1}$, whereas the content of any cytochrome was maximally doubled. Hence, it is not possible to attribute a particular cytochrome content to a certain oxygen uptake rate.

When the dilution rate was increased above $0 \cdot 16 \mathrm{~h}^{-1}$, the steady state content of all cytochromes dropped considerably. It is, however, remarkable that the content of cytochromes $b$ and $c$ under glucose-repressed conditions corresponded roughly to that at low dilution rates (below $0 \cdot 1 \mathrm{~h}^{-1}$ ) in the glucose-derepressed state. Cytochrome $a$ was the only cytochrome whose lowest level was clearly under glucose repression. Again, the change in cytochrome content is not reflected in the oxygen uptake rate. The oxygen uptake rate did not decrease above the dilution of $0 \cdot 16 \mathrm{~h}^{-1}$, but instead remained approximately constant. 


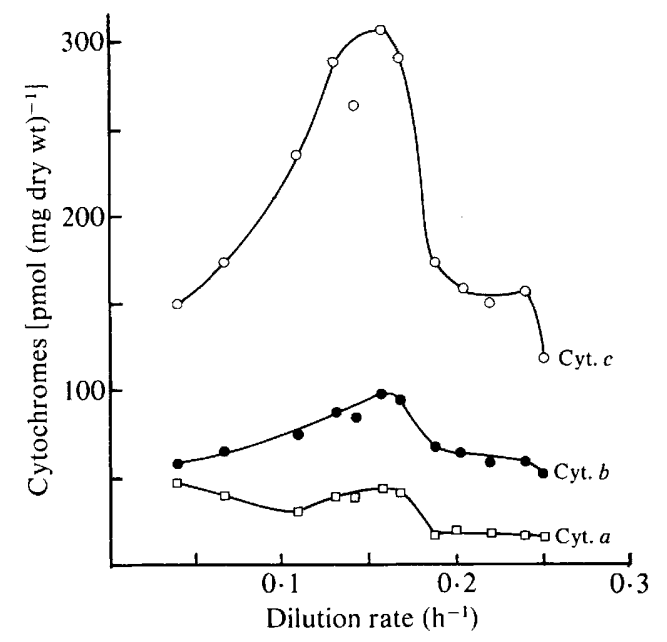

Fig. 2. Steady state mitochondrial cytochrome content of $S$. uvarum as a function of dilution rate in a chemostat culture.

\section{Kinetics of glucose repression}

Both the short-term and long-term kinetics of glucose repression were investigated. The shortterm responses were determined after administering a glucose pulse to glucose-derepressed cells. The long-term kinetics were assessed by an upward shift in dilution rate from the glucosederepressed region into the glucose-repressed one. The response of the culture to these changes was recorded by monitoring the specific gas exchange rates, ethanol, acetate and biomass concentrations, as well as the mitochondrial cytochrome contents.

\section{Glucose pulse}

The response of the overall culture parameters on a glucose pulse is shown in Fig. 3. After the pulse, ethanol and acetate were formed immediately. Acetate always occurred when repressed growth was initiated, but disappeared later on and was never observed under steady state conditions (see Fig. 5). According to this partly incomplete oxidation of glucose, the R.Q. value rose above unity and increased steadily as long as glucose was present. The biomass concentration did not change significantly over the whole period. The course of the oxygen uptake rate clearly indicated that there was definitively no repression of overall respiration. The oxygen uptake rate increased as was the case for the carbon dioxide production rate, however to a lesser extent. Of the cytochrome contents, only that of cytochrome $c$ slightly decreased (Fig. 4). For all the other cytochromes, no change occurred.

From the data of the glucose pulse (Figs 3 and 4), it can be concluded that the change from completely to partly oxidative glucose metabolism in $S$. uvarum is not the consequence of repression of respiration, but begins before any decrease in the overall respiration or cytochrome content of the cells takes place. Therefore, we postulate that ethanol and acetate formation, respectively, are primarily governed by a regulation of the two enzymes pyruvate decarboxylase and pyruvate dehydrogenase, which stand at the beginning of two competitive pathways proceeding from pyruvate. The former leads to ethanol formation and the latter yields acetylCoA, the link to complete oxidation. The change to ethanol formation seems to be the consequence of a limited respiratory capacity of the cells (maximum oxygen uptake rate of approximately $5.5 \mathrm{mmol} \mathrm{g}^{-1} \mathrm{~h}^{-1}$ ), leading to an increased pyruvate pool concentration and the subsequent degradation of pyruvate via the pyruvate decarboxylase pathway. 


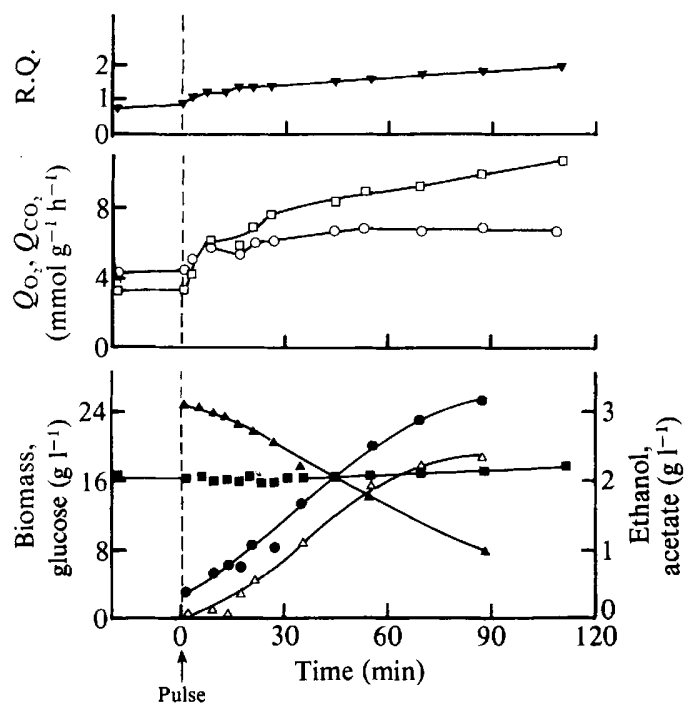

Fig. 3. Short-term response of $S$. uvarum to excess glucose as initiated by a glucose pulse to derepressedgrowing cells. $\square$, Biomass; $\Delta$, glucose; 0 , ethanol; $\triangle$, acetate; $O, Q_{\mathrm{O}_{2}} ; \square, Q_{\mathrm{CO}_{2}} ; \boldsymbol{\nabla}, \mathrm{R}$.Q. The dilution rate of the chemostat was $0 \cdot 1 \mathrm{~h}^{-1}$ and the initial glucose concentration $S_{0}=30 \mathrm{~g} \mathrm{l}^{-1}$. At zero time $25 \mathrm{~g}$ glucose $\mathrm{1}^{-1}$ was added.

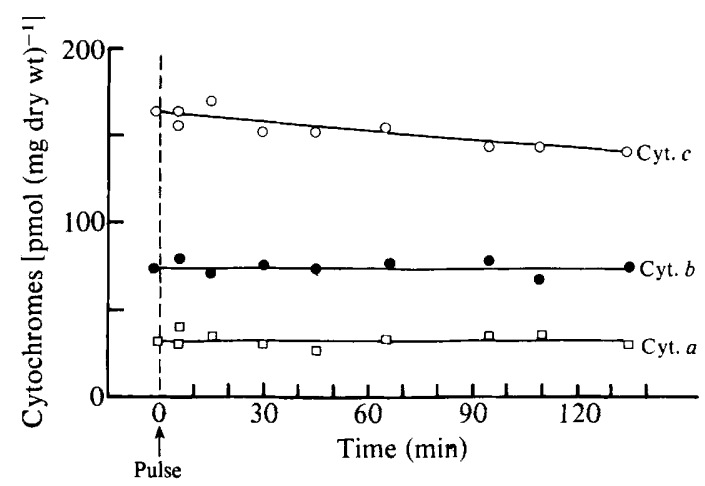

Fig. 4. Short-term response of the mitochondrial cytochrome content of $S$. uvarum to excess glucose as initiated by a glucose pulse to derepressed-growing cells. The conditions of the chemostat culture were the same as in Fig. 3 .

\section{Shift in dilution rate}

In order to elucidate the long-term adaptation of $S$. uvarum to repressed growth conditions, a shift in dilution rate from 0.14 to $0.21 \mathrm{~h}^{-1}$, i.e. from derepressed to repressed growth, was carried out (Fig. 5). The biomass dropped within $45 \mathrm{~h}$ to the level of repressed growth. Ethanol production started immediately after the dilution rate shift and again acetate accumulated at the beginning of the initiation of repressed growth. The R.Q. increased continuously from unity to approximately three after $45 \mathrm{~h}$. Again, the oxygen uptake rate showed no repression after the shift and remained at the level of the corresponding steady state rate (see Fig. 1). The change in R.Q. was mainly due to the increased carbon dioxide production rate which increased from 5 to about $15 \mathrm{mmol} \mathrm{g}^{-1} \mathrm{~h}^{-1}$ in the new steady state. 

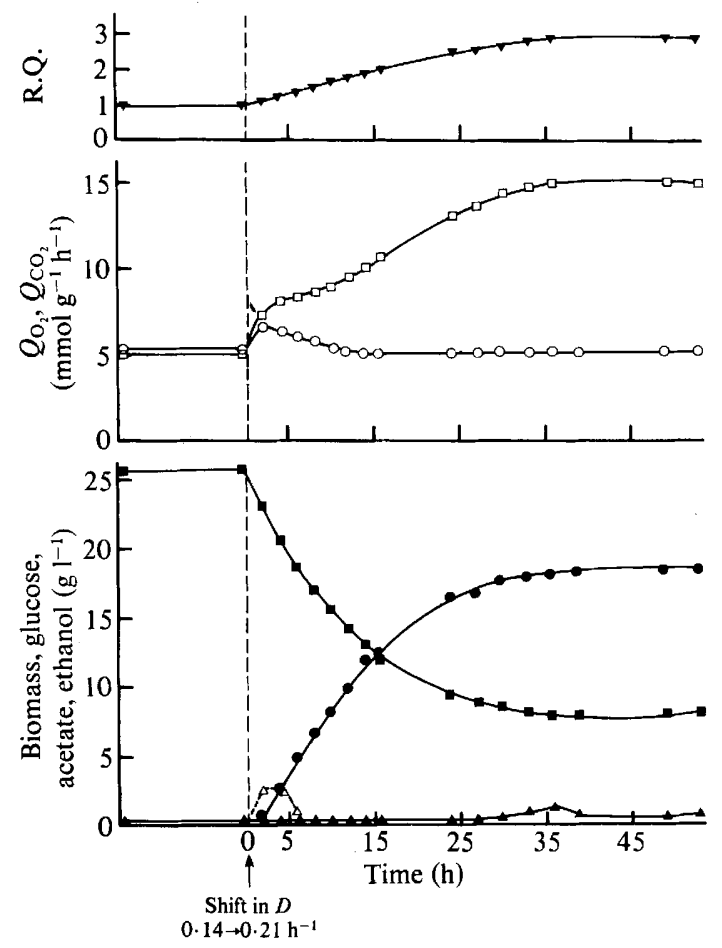

Fig. 5. Long-term adaptation of $S$. uvarum to repressed growth as initiated by a shift in dilution rate from derepressed to repressed growth conditions. $\square$, Biomass; $\boldsymbol{\Delta}$, glucose;, , ethanol; $\triangle$, acetate; $O$, $Q_{\mathrm{O}_{2}} ; \square, Q_{\mathrm{CO}_{2}} ; \nabla$, R.Q. The initial glucose concentration $S_{0}=55 \mathrm{~g}^{-1}$.

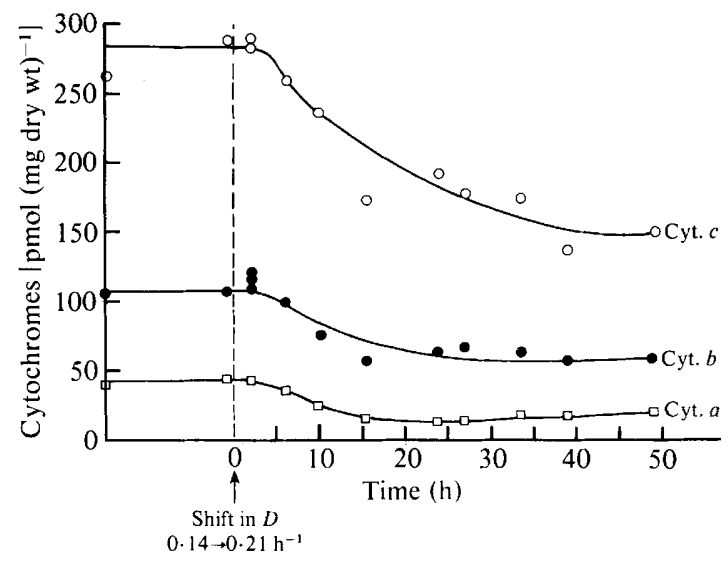

Fig. 6. Long-term adaptation of the mitochondrial cytochrome content of $S$. uvarum to repressed growth as initiated by a shift in dilution rate from derepressed to repressed growth conditions.

The content of all measured cytochromes dropped to a lower level (Fig. 6). It is, however, remarkable that the decrease of mitochondrial cytochrome content started at approximately $2 \mathrm{~h}$ after the shift in dilution rate. This substantiates the evidence from the glucose pulse that the formation of ethanol is not the consequence of a repression of mitochondrial functions, but 
occurs before any change in respiration is observed, as measured by the oxygen uptake rate or by the cytochrome content.

There is, however, a long-term adaptation of the cells to repressed growth which takes place within 24 to $48 \mathrm{~h}$ after its introduction. A slow decrease of the mitochondrial cytochrome content is characteristic for this adaptation process. Considering the relatively long time period required for the mitochondrial cytochrome content to reach the level corresponding to repressed growth, it is difficult to attribute this adaptation to a complete cessation of mitochondrial cytochrome synthesis. Such a repression would lead to a faster disappearance of the cytochromes at the dilution rate of $0.21 \mathrm{~h}^{-1}$. However, this behaviour could originate from a gradually diminishing synthesis of mitochondrial cytochromes.

The data presented above show that a proper analysis of the growth of a glucose-sensitive yeast under defined conditions yields a remarkable insight into the phenomenon generally referred to as glucose repression, a term that certainly needs to be re-evaluated. This type of approach would be of great importance to genetic work in the area. The conclusions often drawn from growth experiments done in complex media where many factors besides glucose may affect enzyme regulation are questionable. In view of our results, it becomes evident that regulation of overall metabolism based exclusively on a repression/derepression pattern inevitably leads to more confusion than clarity, as has been demonstrated by Ciriacy \& Breitenbach (1979). More comprehensive work which takes into account all possibilities for metabolic regulation needs to be done in order to elucidate the particular behaviour of glucose-sensitive yeasts.

This research was supported by grants of the Swiss National Foundation nos 3.465-0.79 and 3.051-0.81.

\section{REFERENCES}

Barford, J. P. \& Hall, R. J. (1979). An examination of the Crabtree-effect in Saccharomyces cerevisiae: the role of respiratory adaptation. Journal of General Microbiology 114, 267-275.

CirIACY, M. (1978). A yeast mutant with glucoseresistant formation of mitochondrial enzymes. $\mathrm{Mo}$ lecular and General Genetics 129, 329-335.

CiriaCY, M. \& BreItenbaCh, J. (1979). Physiological effects of seven different blocks in glycolysis in Saccharomyces cerevisiae. Journal of Bacteriology 139, 152-160.

Duntze, W., Neumann, D., Gancedo, J. M., AtzpoDIEN, W. \& HOLZER, H. (1969). Studies on the regulation and localization of the glyoxylate cycle enzymes in Saccharomyces cerevisiae. European Journal of Biochemistry 10, 83-89.

ENTIAN, K.-D. (1980). A defect in carbon catabolite repression associated with uncontrollable and excessive maltose uptake. Molecular and General Genetics 179, 1969-1975.

Fiechter, A., FuhrmanN, G. F. \& KÄPPELI, O. (1981). Regulation of glucose metabolism in growing yeast cells. Advances in Microbial Physiology 22, 123183.

GMÜNDER, F. K., KÄPPELI, O. \& FIECHTER, A. (1981). Chemostat studies on the hexadecane assimilation by the yeast Candida tropicalis. II. Regulation of cytochromes and enzymes. European Journal of Applied Microbiology and Biotechnology 12, 135142.

Linnane, A. W., Haslam, J. M., Lukins, H. B. \& NAGLEY, P. (1972). The biogenesis of mitochondria in microorganisms. Annual Review of Microbiology 26, 163-198.
Montenecourt, B. C., Kuo, S.-C. \& Lampen, J. O. (1973). Saccharomyces mutants with invertase formation resistant to repression by hexoses. Journal of Bacteriology 114, 223-228.

Perlman, P. S. \& MahleR, H. R. (1974). Derepression of mitochondria and their enzymes in yeast : regulatory aspects. Archives of Biochemistry and Biophysics 162, 248-271.

Polakis, E. S. \& Bartley, W. (1965). Changes of enzyme activities in Saccharomyces cerevisiae during growth on different carbon sources. Biochemical Journal 97, 284-297.

RYTKA, J., SLEdIZIEWSKI, A., LITWINSKA, J. \& BILINSKI, T. (1976). Haemoprotein formation in yeast. II. Isolation of catalase regulatory mutants. Molecular and General Genetics 145, 27-42.

SchamhaART, D. J. H., Ten Berge, A. M. A. \& VAN DE Poo, K. W. (1975). A spontaneous catabolite repression insensitive mutant in Saccharomyces. Journal of Bacteriology 121, 247-260.

vaN WiJK, R., OUWEHAND, H., van de Bos, T. \& KONINGSBERGER, V. V. (1969). Induction and catabolite repression of alpha-glucosidase synthesis in protoplasts of Saccharomyces carlsbergensis. Biochimica et biophysica acta 186, 178-191.

WitT, J., Kroman, R. \& Holzer, H. (1966). Repression von Alkoholdehydrogenase Malatdehydrogenase, Isocitratlyase und Malatsynthase in Hefe durch Glucose. Biochimica et biophysica acta 118, 522-537.

ZimmermanN, F. K. \& Eaton, N. R. (1974). Genetics of induction and catabolite repression of maltase synthesis in Saccharomyces cerevisiae. Molecular and General Genetics 134, 261-272. 